
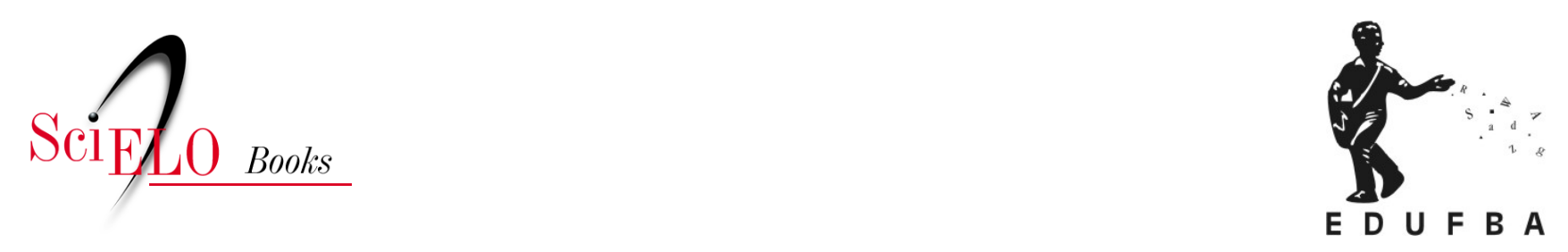

\title{
As organizações do Movimento Negro e o processo de implementação da Política Nacional de Saúde Integral da População Negra (2006-2014)
}

\author{
Marcos Vinícius Ribeiro de Araújo \\ Carmen Fontes Teixeira
}

\section{SciELO Books / SciELO Livros / SciELO Libros}

ARAÚJO, M.V.R., and TEIXEIRA, C.F. As organizações do Movimento Negro e o processo de implementação da Política Nacional de Saúde Integral da População Negra (2006-2014). In: TEIXEIRA, C.F., comp. Observatório de análise política em saúde: abordagens, objetos e investigações [online]. Salvador: EDUFBA, 2016, pp. 187-225. ISBN 978-85-232-2021-1.

https://doi.org/10.7476/9788523220211.0007.

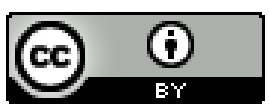

All the contents of this work, except where otherwise noted, is licensed under a Creative Commons Attribution 4.0 International license.

Todo o conteúdo deste trabalho, exceto quando houver ressalva, é publicado sob a licença Creative Commons Atribição $\underline{4.0}$. 


\section{AS ORGANIZAÇÕES DO MOVIMENTO NEGRO E O PROCESSO DE IMPLEMENTAÇÃO DA POLÍTICA NACIONAL DE SAÚDE INTEGRAL DA POPULAÇÃO NEGRA (2006-2014)}

\section{Introdução}

A formulação de políticas públicas dirigidas aos problemas de saúde prevalentes em determinados grupos sociais não se configura como uma novidade no âmbito do sistema público de saúde brasileiro. A discussão sobre a saúde da mulher e seus direitos reprodutivos, nos anos 1980, na qual se destaca a problemática das mulheres negras, a saúde indígena e a epidemia de aids, de alguma forma expressam a conjuntura mundial de duas décadas anteriores que colocaram na cena política do ocidente, a participação de novos atores sociais e políticos, mobilizados pela problemática de gênero, raça e sexualidade, para citar alguns. (BERNARDES, 2011; MELLO et al., 2011; OSIS, 1998)

A partir de então, a consolidação de movimentos sociais e ações coletivas em torno dessas pautas passaram a ter destaque no Brasil, 
colocando em evidencia temas até então negligenciados, influenciando nas décadas seguintes a formulação de políticas públicas de saúde com esses recortes. É nesse contexto que emerge a temática da saúde da população negra e, no início do século XXI, o surgimento de uma política nacional de saúde voltada para esse setor que compõe mais de $50 \%$ da população brasileira.

Embora seja conhecida a participação dos movimentos sociais na construção de agendas governamentais, inclusive das organizações do Movimento Negro em relação a políticas de saúde voltadas para população negra (ALMEIDA, 2013; BRASIL, 2011; ARAUJO; TEIXEIRA, 2013), pouco se sabe sobre a participação desses atores no processo de implementação de uma determinada política pública, uma vez que essa fase é dominada majoritariamente pelos técnicos do governo, embora possam dela participar representantes dos movimentos sociais.

Assim, este capítulo, resultado de uma investigação sobre o discurso de lideranças do Movimento Negro atuantes no campo da saúde, busca desenvolver um olhar sobre a participação das principais organizações da sociedade civil de atuação nacional, vinculadas a esse movimento, no processo de implementação da Política Nacional de Saúde Integral da População Negra (PNSIPN) entre 2006 a 2014.

\section{Breve resgate histórico da atuação do Movimento Negro no Brasil: a aproximação com as políticas de saúde}

A aprovação da Lei Áurea, embora tenha formalmente extinguido a escravidão no Brasil, não implicou em mudanças significativas nas condições de vida da grande maioria da população negra brasileira. Pelo contrário, a legislação que vigorou até a primeira metade do século XX em diferentes momentos, reforçou um processo de marginalização dos negros (JACCOUD, 2008), ao tempo em que as políticas econômicas e sociais implementadas pelo Estado, praticamente ignoraram os problemas enfrentados por esse segmento populacional, 
contribuindo, assim, para reforçar as desigualdades raciais e sociais existentes no país. (FERRAZ; SANTOS FILHO, 2007)

Ainda assim, um conjunto de associações, clubes, organizações filantrópicas e beneficentes voltadas para a população negra, durante esse período, buscavam a inclusão, ascensão social e participação igualitária dos negros em instâncias de poder nacional. (SILVA, 2011) Organizações como a Frente Negra Brasileira, indicavam representações negras em cargos eletivos, bem como, buscavam a inserção de negros no âmbito parlamentar (estaduais ou municipais) para aliarem-se aos quadros da organização. (SILVA, 2003)

Apesar disso, o combate ao racismo, especificamente, recebeu pouca atenção por parte dos governos na primeira metade do século XX. Mesmo com a Lei Afonso Arinos, em 1951, considerada a primeira lei penal sobre discriminação no Brasil, e, portanto um ponto de apoio importante na "luta antirracista", as ações por parte do Estado não se tornaram mais incisivas em coibir as ações racistas no Brasil. (GRIN; MAIO, 2013)

A partir dos anos 1960, as lutas e conquistas do Movimento Negro americano pelos direitos civis influenciam diretamente o Movimento Negro brasileiro, constituído nos anos 1970 (TRAPP; SILVA, 2010), no bojo do fortalecimento das lutas sindicais e populares que marcaram o processo de resistência à Ditadura Militar e luta pela democratização política do país. Com o surgimento do Movimento Negro Unificado (MNU ), o debate sobre a problemática racial ganhou maior espaço na sociedade civil, a partir da denúncia do mito da "democracia racial" no país e da exigência da criação e extensão dos direitos sociais para a população negra. (DOMINGUES, 2007; KÖSSILING, 2007)

Em 1985, o Movimento conseguiu uma importante conquista com a lei 7.437/85, a chamada Lei CAO, que substituiu a Lei Afonso Arinos, incluindo entre as contravenções penais, a prática e atos resultantes de preconceito de raça, de cor, de sexo ou de estado civil, sendo essa lei considerada o embrião do artigo $\mathrm{V}$ da Constituição Federal elaborada três anos mais tarde. (GUIMARÃES, 2001) No que se 
refere às questões específicas do tema racial, a Constituição Federal de 1988 passa a caracterizar a prática de racismo como crime inafiançável e imprescritível, sujeito à pena de reclusão, além de reconhecer a propriedade definitiva das terras aos remanescentes de quilombos que estivessem ocupando suas terras, e o direito à preservação da cultura dessa população. (GUIMARÃES, 2001; PIANA, 2009)

Como se sabe, a aprovação da "constituição cidadã" implicou na adoção de políticas sociais universais, a exemplo da criação do Sistema Único de Saúde (SUS), bem como na expansão dos serviços e benefícios da assistência social, gratuidade, estabelecimento da obrigatoriedade do ensino fundamental, reconhecimento dos direitos previdenciários. (FLEURY; OUVERNEY, 2008) Face à persistência de desigualdades raciais no acesso a bens e serviços, essas políticas foram consideradas insuficientes pelo Movimento Negro, o qual passou a priorizar em sua agenda, a análise das políticas públicas sob a ótica racial. Vale destacar que ainda nos anos 1980, surgiram as primeiras intervenções do Movimento de Mulheres Negras, a partir da atuação das ativistas desse movimento sobre a problemática dos direitos sexuais e reprodutivos, nos espaços institucionais das secretarias municipais e estadual no Estado de São Paulo. (MAHER, 2005; PINTO; SOUZAS, 2002)

Com a Marcha Zumbi dos Palmares contra o Racismo, pela Cidadania e pela Vida, que reuniu cerca de 30 mil pessoas em Brasília em 20 de novembro de 1995, o Movimento Negro apresentou uma carta ao Estado, contendo suas principais reivindicações e demandas, o que gerou a criação do um Grupo de Trabalho Intersetorial para a Valorização da População Negra. A conformação desse grupo contemplou um subgrupo específico de Saúde da População Negra que passou a se responsabilizar pela elaboração e implantação de ações nessa área. (LEITÃO, 2012)

Em 1996 esse grupo de trabalho realizou uma reunião técnica sobre Saúde da População Negra, contando com a participação de vários pesquisadores, dirigentes e profissionais de saúde e militantes do Movimento Negro, com o objetivo de discutir políticas afir- 
mativas para a população negra no campo da saúde. (OLIVEIRA, 2001) A partir daí, foi criado o Programa de Anemia Falciforme no âmbito do Ministério da Saúde (MS) e incorporado o quesito cor nos instrumentos de informação em saúde, destacando-se a variável raça nos estudos sobre a prevalência de doenças como diabetes mellitus, hipertensão arterial, miomas e anemia falciforme na população feminina, além de discutirem os efeitos do racismo na produção das desigualdades em saúde, inclusive no acesso e qualidade dos serviços prestados no âmbito do SUS. (ADORNO; ALVARENGA; VASCONCELLOS, 2004)

Mas é a partir da III Conferência Mundial contra o Racismo, Discriminação Racial, Xenofobia e Intolerância Correlata, realizada em Durban, na África do Sul, em setembro de 2001, que os ativistas da questão da saúde da população negra, ampliam sua mobilização e com apoio da Programa das Nações Unidas para o Desenvolvimento da Organização das Nações Unidas (PNUD/ONU) conseguem aprofundar essas discussões junto ao governo brasileiro. (CARNEIRO, 2002; BENTES, 2002; LOPES, 2005)

O marco desse processo é o documento produzido a partir do Workshop Interagencial sobre Saúde da População Negra, em Brasília, no ano de 2001, por iniciativa do PNUD e da Organização Pan-Americana da Saúde (OPAS), que contou com a presença de diversos profissionais de várias organizações internacionais, do Movimento Negro e de representantes da academia. O documento reconhece a ausência do MS no enfrentamento das questões raciais e define a área de saúde da população negra como uma área de estudo inter e transdisciplinar. Ainda, parte da constatação de que o racismo e a discriminação racial expõem mulheres e homens negros a situações mais perversas de vida e de morte e argumenta que estas só podem ser modificadas pela adoção de políticas públicas capazes de reconhecer os múltiplos fatores que resultam em condições desfavoráveis de vida. (ORGANIZAÇÃO PANAMERICANA DA SAÚDE, 2001) 
Esse documento também é a base para a construção da PNSIPN (ALMEIDA, 2013; BRASIL, 2011), aprovada por unanimidade no Conselho Nacional de Saúde (CNS), em 2006, consolidando assim a responsabilidade do SUS em promover ações favoráveis à saúde da população negra, considerando que, apesar das conquistas institucionais do Movimento Negro, o racismo, como condição histórica, imersa na cultura brasileira, segue agravando a vulnerabilidade desse segmento populacional. (BRASIL, 2011)

Em 2009, foi instituída, por meio de portaria MS n. ${ }^{\circ} 992 \backslash 2009$, a PNSIPN, cujo objetivo é "promover a saúde integral da população negra, priorizando a redução das desigualdades étnico-raciais, o combate ao racismo e à discriminação nas instituições e serviços do SUS”. Inclui ainda nos seus objetivos específicos “o acesso da população negra do campo e da floresta, em particular as populações quilombolas, às ações e aos serviços de saúde”. (BRASIL, 2009) No ano seguinte, com a aprovação da lei n. ${ }^{\circ}$ 12.288/10, que institui o Estatuto da Igualdade Racial, marcado por intensos conflitos entre as organizações do Movimento Negro, foi aprovado o capítulo da saúde baseada na portaria do MS, ampliando assim a abrangência da responsabilidade do Estado sobre a temática.

As diferentes conjunturas político-governamentais nas quais se desenvolveram as ações do Movimento Negro, em relação às suas pautas de ação afirmativa, e particularmente da saúde da população negra, não foram, portanto, empecilhos para que fossem formuladas políticas públicas voltadas à intervenção sobre a realidade vivenciada pela população negra no Brasil, ainda que guardada as devidas particularidades. Para Lima (2010), os anos do governo Fernando Henrique Cardoso (FHC) marcaram uma relação de "exterioridade" na relação entre o Movimento Negro e o Estado, sendo ao movimento reservado um papel de demandante e pouca inserção no aparato governamental, ao contrário do governo Lula que incorporou quadros do Movimento Negro no governo, tanto ocupando cargos como representando a sociedade civil nos espaços de controle social. 
A aprovação da PNSIPN no CNS, em 2006, a publicação da portaria em 2009, e a aprovação do capítulo de saúde na lei do Estatuto da Igualdade Racial, constituem o marco legal a partir de onde se desenvolve o processo de implementação dessa política. Fase esta que não se resume à execução de ações meramente administrativas, mas o momento de "colocar em prática as soluções apontadas", o que envolve questões estratégicas relativas aos interesses de múltiplos atores. (PINTO; VIEIRA-DA-SILVA; BAPTISTA, 2014)

Portanto, nem todas as decisões relevantes são definidas durante as fases de formulação, pois envolvem conflitos, negociações e compromissos com interesses antagônicos. Assim, uma definição feita em fase anterior pode ser modificada ou mesmo rejeitada e alterar o argumento principal da política; novas negociações são processadas e por consequência novas decisões e formulações são apresentadas reiniciando assim o ciclo. Como assinalam Viana e Baptista (2008, p. 101)

[...] se o momento de formulação é uma ocasião dos grandes consensos, em que tudo é possível, é no momento de implementação que se descobre a real potencialidade de uma política, quem são os atores que a apoiam, o que cada um dos grupos disputa e seus interesses.

\section{As relações entre Estado e organizações da sociedade civil}

O ponto de partida para a construção do referencial teórico desse estudo foi a revisão das contribuições da teoria gramsciana, utilizada por um conjunto de autores brasileiros da área de ciências políticas (COUTINHO, 1993; NOGUEIRA, 1999; SEMERARO, 2006), inclusive na Saúde Coletiva, em estudos de políticas de saúde. (PAIM, 2008)

Gramsci (2000) desenvolve o conceito de Estado que está para além do governo administrativo. O Estado ampliado é o somatório 
da sociedade política mais a sociedade civil, tratando-se de uma unidade-distinção, uma vez que guardada as devidas características, essas instâncias não se constituem oposição. A sociedade política é constituída pelo "[...] conjunto dos mecanismos através dos quais a classe dominante detém o monopólio legal da coerção; trata-se daquilo que muitas vezes se chama de Estado em sentido estrito ou Estado-coerção, formado pelas burocracias ligadas às forças armadas e à aplicação das leis, ou seja, o governo [...]”. (COUTINHO, 2011, p. 25) Por sua vez, a sociedade civil é o espaço em que as classes se organizam, elaboram e difundem valores, cultura e ideologias, através de partidos, sindicatos, associações, igreja, imprensa, escolas etc., confrontando projetos de sociedade.

Essa concepção coloca em evidência a complexidade do Estado, que, em seu desenvolvimento histórico, na fase capitalista, passa a buscar outras formas de manutenção de poder, não se restringindo ao uso da força. Para Gramsci (2000, p. 331), “[...] o Estado é todo o complexo de atividades práticas e teóricas com as quais a classe 194 dirigente não só justifica e mantém seu domínio, mas consegue obter o consenso ativo dos governados [...]". Segundo Vasconcelos, Silva e Schamller (2013, p. 87) essa compreensão revela a concomitante função do Estado: assegurar as condições necessárias à expansão da economia e "educar para alcançar o consenso".

Assim, a função primordial do Estado se define na garantia da hegemonia da classe dominante. Hegemonia compreendida não como dominação, mas como capacidade de direção, de obter e manter poder sobre todos os aspectos da sociedade, político, econômico, ideológico, fundamentada no consenso, ou seja, fazendo os interesses da classe dominante parecerem como universais, garantido, de maneira consentida, por meio do apoio e legitimação das massas. (COUTINHO, 1993)

Porém, esse processo não ocorre de maneira unilateral e mecânica, ao contrário é um processo dinâmico marcado por disputas e lutas entre as classes e no interior das próprias classes, assim como também não se trata de um processo natural, e conta com a mediação 
da política. Na perspectiva gramsciana, as realidades históricas são construções que se transformam, sendo dependentes da intervenção humana, resultando, portanto, das variadas dimensões das relações de forças, da organização e consciência dos grupos sociais, e da práxis individual e coletiva. (SEMERARO, 2006)

Nesse sentido, as ideologias, entendidas como visão de mundo, “[... 'organizam' as massas humanas, formam o terreno no qual os homens se movimentam, adquirem consciência de sua posição e lutam" (GRAMSCI, 1999, p. 237), processo este que abre espaço para o desenvolvimento da autoconsciência e a organização dos diferentes grupos. Ainda segundo o autor, o grau de consciência política envolve três diferentes fases. A primeira refere-se ao momento econômico-corporativo ou "egoístico passional"; a segunda, a um momento de solidariedade de interesses entre grupos, mas ainda no campo econômico; e a terceira remete ao momento "ético-político", de superação das necessidades corporativas e a sua universalização, sintetizada na "catarse". (GRAMSCI, 2000)

Desse modo, em meio às contradições características da própria luta entre as classes, desenvolvem-se as práticas políticas das organizações da sociedade civil. A manutenção do poder da classe dominante não prescinde de estratégias que atraiam para o seu campo as demais camadas de intelectuais e partidos, produzindo aquilo que é denominado de transformismo. Segundo Coutinho (2010, p. 38), o transformismo envolve "[...] um processo de cooptação das lideranças políticas e culturais das classes subalternas", excluindo-as "de todo efetivo protagonismo nos processos de transformação social”, que, aliada ao consenso passivo, leva as massas a naturalizarem a ordem constituída, sem visualizarem possibilidades de transformação. Em suma, as relações que se estabelecem entre as organizações da sociedade civil e o Estado podem ser de conservação, reprodução ou transformação da ordem política, econômica e social.

Com base no que foi exposto até aqui, compreendemos o Movimento Negro como uma organização que aglutina segmentos oriundos das classes subalternas, no âmbito da sociedade civil, 
e também desenvolve uma práxis no campo da saúde, podendo se constituir como conservador ou reprodutor do modo como as políticas públicas abordam a saúde da população negra ou desempenhar um papel transformador dessas políticas, quer contribuindo para a introdução de temas específicos e/ou concepções inovadoras e mais abrangentes, que vinculem as questões de saúde aos determinantes sociais e políticos que incidem especificamente sobre essa população, a exemplo do racismo.

\section{A contribuição do pensamento estratégico em saúde para a análise das lideranças dos movimentos sociais enquanto atores da ação institucional}

Estudos sobre movimentos sociais contemporâneos (GOHN, 2011) apontam que, a partir da década de 1990, ocorreu um aumento cada vez maior da atuação dessas organizações, bem como das Organizações Não Governamentais (ONGs) e sindicatos, em diversos espaços institucionais, a exemplo de conselhos gestores e comitês técnicos, (PINTO, 2006; RAMOS, 2004; TORRONTEGUY; DALLARI, 2012), atuando como portadores de inúmeras demandas sociais.

Na medida em que as organizações do Movimento Negro participam desse processo, constata-se que as relações que vêm se estabelecendo entre tais organizações e os gestores e técnicos que atuam em diversos espaços institucionais influenciam o processo de implementação da PNSIPN, demonstrando tanto as correlações de forças estabelecidas nesse processo como a capacidade do Movimento de superar (ou não) uma pauta corporativa. (LEITÃO, 2012; RIOS, 2012)

Considerando a importância de se levar em conta a análise da ação institucional, dos atores políticos do Movimento Negro, que participam da disputa pelo poder, acionando estratégias no âmbito institucional, torna-se relevante a incorporação de conceitos provindo do pensamento estratégico em saúde desenvolvida por Mário Testa (1995), autor que, nas últimas três décadas, vêm sub- 
sidiando os estudos na área de política, planejamento e gestão no campo da saúde coletiva.

Para Testa (1995), a instituição é uma organização, onde é estabelecida uma série de estruturas e sistemas formais e informais, cuja coerência é assegurada por associações de ideias, valores e crenças de diferentes grupos de poder, conforme a capacidade de traduzir seus interesses em arranjos organizacionais. Por trás das questões organizacionais e administrativas, sempre estarão relações de poder, entendido, por esse autor, como a capacidade geral de agir e produzir efeitos e também de determinar o comportamento de outro(s) indivíduo(s), ou seja, fazer com que este realize a sua própria vontade mesmo contra a resistência deste ou de outros que participam da ação. Essa capacidade implica em manipular recursos (poder administrativo), informações (poder técnico) e interesses (poder político), que estão alocados nas mãos de algumas pessoas, grupos sociais e instituições. (TESTA, 1992)

Nessa perspectiva, as mudanças na forma de enfrentamento dos problemas de saúde passam pela mudança do comportamento dos atores sociais. Para entrar no jogo, em condições de obter triunfo sobre aqueles que se opõe a uma determinada política, é necessário que "os competidores", os sujeitos, possuam alguma forma de poder. Nesse sentido, a estratégia não pode ser compreendida como simples meio para se alcançar um determinado fim e torna-se um conceito operacional que permite identificar a disponibilidade de poder de cada grupo. Trata-se do comportamento de um ator social (indivíduo, grupo, instituição) cujo objetivo é adquirir liberdade de ação que lhe permita ganhar espaço de manobra para implementar os objetivos buscados. Esses objetivos são os conteúdos específicos da política que, para esse autor, é uma proposta de distribuição de poder. (TESTA, 1992)

Assim, a participação dos diversos atores na formulação e implementação de políticas de saúde pode configurar uma processo que implique deslocamento e/ou consolidação do poder de grupos sociais concretos, que, através de suas lideranças possam produzir 
consensos em torno da incorporação de conteúdos específicos na política, bem como desenvolver ações que viabilizem a formação de alianças que debilitem o poder dos grupos que se opõem a essa política. Por fim, na perspectiva de Testa, uma proposta de mudança social não pode ser efetivada apenas por mudanças setoriais; entretanto, estas podem criar condições para abrir caminhos para a modificação esperada. A análise das práticas políticas dos atores da sociedade civil envolvidos no desenvolvimento desses processos pode fornecer subsídios para se compreender as potencialidades desses espaços na perspectiva da transformação.

Em síntese, os sujeitos coletivos se transformam em atores no contexto da ação estratégica; a partir da problematização das relações sociais, reivindicação de espaços de poder e luta por transformações, envolvem-se na decisão política (sociedade política) ou no desenho estratégico das ações nos diversos terrenos da atividade social (sociedade civil) (RIVERA, 1995), perspectiva a partir da qual ganha inteligibilidade a ação institucional dos atores do Movimento Negro.

\section{Racismo, saúde e Estado: o olhar das lideranças da sociedade civil}

As entidades do Movimento Negro no Brasil são caracterizadas pela sua diversidade e heterogeneidade, no que diz respeito às suas pautas, suas estruturas político-organizativas e mesmo suas orientações ideológicas, porém comungam entre si a atuação política no enfrentamento das condições desiguais e perversas as quais estão submetidas a população negra.

Dentre as principais organizações à frente dos processos de formulação e implementação da PNSIPN nos últimos anos, destacam-se a Associação Cultural de Mulheres Negras (ACMUN), Geledés Instituto da Mulher Negra, Criola, Federação Nacional de Associações das Pessoas Com Doença Falciforme (Fenafal), União dos Negros pela Igualdade (Unegro), Rede Nacional de Religiões Afro-Brasileiras e Saúde (Renafro). Em sua maioria, essas lideranças 
feministas negras vêm atuando nos últimos 20 anos no campo da saúde, articulando o debate entre o racismo e a saúde no Brasil

Para esse conjunto de lideranças, o racismo é considerado principal elemento que afeta as condições de saúde da população negra no Brasil. Enquanto ideologia, segue existindo na sociedade brasileira, tendo se tornado mais visível a partir do aumento do número de denúncias feitas por parte de pessoas negras, vítimas de discriminação racial. Persistindo as desigualdades raciais, impondo diferenças entre negros e brancos ainda que a população negra venha alcançando algumas melhorias no acesso ao mercado de consumo.

O racismo está onde sempre esteve, atuando violentamente contra nós [...] ao mesmo tempo ele está mais visivel, mais desnaturalizado [...]. (CRIOLA)

[...]... eu acho que o racismo sofre um recrudescimento [...] talvez pela própria divulgação de dados, pela visibilização dos negros, ocupando espaços ou ocupando pouquíssimos espaços, mas disputando espaços [...] Parece que o pessoal saiu do armário, sabe assim?! (GELEDES)

[...]

Nos últimos dez anos o racismo foi mais denunciado... (UNEGRO)

o racismo cada vez vai ficando mais forte. Ainda que nós, população negra, [por mais que] estejamos alcançando alguma mobilidade social. [...] não conseguimos alcançar patamares como o da população branca. (RENAFRO)

Apesar dessa análise sobre a persistência do racismo na sociedade brasileira, para elas, nos últimos 10 anos, houve avanços na atuação do Governo Federal em relação a governos anteriores, notadamente em função de uma maior abertura política para debater o tema. Apesar disso, consideram que as ações governamentais ainda são insuficientes, sobretudo quando se trata de investimento de 
recursos financeiros, humanos e logísticos nas ações que coíbam o racismo e promovam a igualdade racial:

Isso não significa que o governo Lula e o governo Dilma foram excepcionais. Não são excepcionais. Mas nós saímos do marco zero. 'Nós vivíamos' no marco zero. (UNEGRO)

[...] não investe o que é preciso, não assume a sua tarefa de agir pelo antirracismo. Eu acho que o governo federal não faz, governos estaduais não fazem, governos municipais menos ainda [...] mas reconheço também que existem algumas ações, eu digo, são ações e como ações são insuficientes, algumas de qualidade e outras não. (CRIOLA)

Eu acho que muito pouco. Eu acho assim é... eu acho que tivemos é... alguns ganhos, né? É claro que é importante [...] a gente não pode dizer que não teve ganho. (RENAFRO)

Ao referirem-se, porém, às políticas de saúde do Governo Federal, a maioria enfatiza o fracasso das políticas em produzir uma mudança do perfil de morbimortalidade da população negra, chamando a atenção para a insuficiência dos recursos, bem como apontando a priorização de ações de alta complexidade e a insuficiência das ações de prevenção e promoção. Uma das lideranças atribui isso à disputa dos interesses do mercado por dentro do Estado, no setor público, responsabilizando o governo pela omissão diante do interesse público.

O orçamento do SUS é o maior orçamento da união então tá sempre em disputa [...] eu acho que a gestão da política não tem tido coragem de ir fundo na defesa do interesse público, e tão sempre negociando, fazendo acordos, mas acordos que terminam por prejudicar $e$ entregar cada vez mais fatias do interesse público ao mercado [...] 
concentram todo o dinheiro da saúde mais em procedimento do que em promoção, porque em procedimento tem uma série de empresários e pessoas que vão ganhar dinheiro, mas em promoção já não tem mais tanta gente. (CRIOLA)

[...] tem dados de que mulheres negras morrem mais de complicações de parto, os casos de AIDS eles diminuem, eles estabilizam, mas não estabilizam na população negra. (ACMUN)

Apesar de todos os avanços, eu acho que o investimento para saúde deveria ser... [maior] [...] Talvez se o investimento fosse maior aí você pensava realmente no que é saúde, que é vida, não em desenvolver política para o adoecimento, porque se você pensa em saúde como vida, você vai pensar em investir para que essas pessoas não adoeçam, que é a prevenção. (FENAFAL)

Em suma, elas apontam para uma situação social de agudização dos problemas, tanto do fortalecimento do racismo quanto da privatização do sistema público de saúde, demonstrando o complexo entrelaçamento dessas duas problemáticas no Brasil. Porém, reconhecem certo avanço nas ações do governo, no âmbito do executivo, um pouco mais nas questões diretamente vinculados ao tema racial do que nas questões da saúde. Essa visão das lideranças fornece pistas sobre a estratégia priorizada, as disputas que estabelecem, suas análises do processo político bem como as dissonâncias e convergências que emergem no processo de implementação da PNSIPN.

\section{Estratégia, política e as disputas ideológicas}

Todas as lideranças expressam que o eixo central da sua estratégia para o acompanhamento da implementação da PNSIPN tem sido a ocupação de espaços em instâncias de gestão participativa e em comissões técnicas criadas no âmbito do SUS. Assim, relatam a ocupação do assento no CNS (ACMUN, Unegro, Fenafal e Renafro), 
instância gestora do SUS ao nível nacional e comentam que, apesar de algumas lideranças terem assento no Comitê Técnico de Saúde da População Negra de (CTSPN) (Criola, Fenafal), alocado na Secretaria de Gestão Participativa do Ministério da Saúde, estrutura institucional destinada ao acompanhamento e decisões técnicas da PNSIPN, percebem haver certa desvalorização dessa instância por parte do governo.

O Conselho Nacional de Saúde tem 64 anos. Tem apenas dois mandatos do conselho que tem a representação do movimento negro... nunca teve... (UNEGRO) ter uma vaga no conselho nacional de saúde significa dizer que tem uma comissão no conselho nacional de saúde dedicada a monitorar pelo lado de dentro ofuncionamento, a implementação da política. (CRIOLA) ... nosso principal espaço para a implementação dessa política né?! É estar no conselho nacional de saúde. Eu acho que a gente avança, quando a gente consegue ampliar essa participação no conselho nacional de saúde [...] (ACMUN)

Dentro do comitê [técnico de saúde da população negra] a gente participa de todo processo de sugestões, de encaminhamentos, da discussão, de como que deve fazer, do que deve mudar, aquilo que deu certo como que tem que incentivar mais a participação dos municípios e dos estados que a missão do comitê né?! [mas] reconhecemos que houve 'um retrocesso', uns dois anos, teve aquele avanço aquele, deu uma parada e que teve uma retomada agora! (FENAFAL)

Ao mesmo tempo, as lideranças constituem alianças, que podem ser provisórias ou permanentes, de acordo com a pauta pleiteada, no intuito de alcançar maior amplitude de suas ações. Essas alianças são construídas com os movimentos sociais, nos Conselhos; com outras instituições governamentais, a exemplo da Secretaria de Políticas de Promoção da Igualdade Racial (Seppir), na articulação com os 
ministérios; e com parlamentares da base do governo do Partido Comunista do Brasil (PC do B) e do Partido dos Trabalhadores (PT), na Câmara Federal dos deputados, na intervenção em temas legislativos de interesse, a exemplo do Estatuto da Igualdade Racial e de peças orçamentárias em relação à política.

[...] exceto nós [organizações que militam em torno da PNSIPN], contamos com o apoio do movimento LGBT em muitos momentos, do movimento do pessoal da terra até então, dos movimentos mais populares a gente contou com apoio, voto! (CRIOLA)

[... na feitura do estatuto de igualdade racial... a deputada Janete Pietá né?! liderou junto com um grupo né?! deparlamentares, da frente parlamentar do antirracismo, frente parlamentar negra [Frente Parlamentar Mista da Igualdade Racial], mas foi ela que nos levou ao debate, foi ela que negociou, que nós negociamos com ela que se o estatuto da igualdade racial vai ter um capitulo de saúde que ele fosse nos mesmos termos com que a gente construiu a política nacional de saúde integral da população negra [...] deputado Luís Alberto, que é do PT, e deputado Daniel Tourinho, PCdoB, e do deputado Carlos Santana, do PT. (CRIOLA)

[estamos] Tentando interferir no orçamento, nos PPAS, na LDO, na LOA, pra introduzir a questão da saúde da população negra. São peças orçamentárias com emendas parlamentares. (UNEGRO)

[...] a SEPPIR nacionalmente tem dialogado com os ministérios pra implementação da política nacionalmente, então são 11 ministérios no grupo intersetorial ministerial para trabalhar a questão da saúde inclusive, no ministério da saúde, não trabalha só saúde, trabalha também outras politicas, mas lá tem saúde, tem técnica lá dentro da SEPPIR. (UNEGRO) 
Chama atenção o fato dessas lideranças apenas considerarem aliados aqueles com os quais estabelecem aliança permanente, baseados em interesses estratégicos comuns, sujeitos diretamente vinculados a PNSIPN e à Seppir. Com relação aos opositores da Política, atribuem termos abstratos como "os racistas", "o resto de mundo", "o governo", discorrendo mais sobre os obstáculos enfrentados ao longo do processo do que necessariamente sobre os sujeitos e/ou organizações que desenvolvem práticas racistas.

Nesse particular, afirmam encontrar resistências em alguns espaços do MS e até mesmo no CNS em relação à temática, sendo acusadas diversas vezes de negarem o princípio da universalidade do SUS em detrimento de uma pauta corporativa. Para as lideranças, fica claro que a intensidade da disputa ideológica no campo da saúde acerca das relações entre o racismo e suas implicações no quadro sociossanitário da população brasileira tem implicações diretas no processo político, delineando a correlação de forças nas decisões acerca da implementação da Política.

[dizem que] a gente fica insistindo em falar coisa de negro e falar de raça quando não tem nada a ver, o SUS é universal, o SUS é pra todo mundo, que a gente tá defendendo uma bandeira particular. (CRIOLA) existem pessoas que estão dentro...que poderiam contribuir e que não contribui por não acreditar que existe o racismo e achar que a gente quer um SUS separado. (FENAFAL)

Esse é o debate que a gente vai pra cima mesmo e eles mantêm. "Mas eu não sou racista, acho que não cabe, vai dividir o SUS" e quem mais divide são eles quando eles ele aprovam determinadas políticas de pesquisa, inclusive, pra determinadas patologias e nunca prevalece a doença falciforme nessa politica (UNEGRO).

Assim a participação no CNS como estratégia prioritária na implementação da PNSIPN, em função da desvalorização do governo 
em relação a CTSPN, as articulações parlamentares, a aliança com a Seppir indicam os caminhos percorridos pelo coletivo de lideranças na disputa ideológica e política em relação às implicações do racismo na saúde da população negra.

\section{0 desenvolvimento do processo político e a percepção das relações de poder}

O processo político que se desenvolve em torno da implementação da PINSPN é marcado por contradições na relação que se estabelece entre o coletivo de lideranças e as instituições do governo vinculadas à questão. Se por um lado estabelecem uma relação de cooperação com a Seppir, com o MS, apresentam constantes tensões do ponto de vista político:

O que acontece que a gente vem acompanhando por um balanço feito inclusive pelo Ministério da Saúde, é que são ações isoladas e descontínuas. E ação isolada e descontinua não chega a lugar nenhum. (RENAFRO)

Tem ações que quando o Ministério da Saúde quer, ou a secretaria quer, eles fazem de um dia pro outro basta um telefonema e as coisas acontecem (GELEDES)

Eu acho que a política não tem sido implementada, não tem havido nenhum investimento. (FENAFAL)

Afinal o SUS que cujo universo com que ele trabalha basicamente pessoas negras né?! então já tá na disputa de que não querem oferecer grande coisa pra 'essa gente' né?! Que eu imagino que éo que deve ser que passar na cabeça daquelas pessoas [gestores].(CRIOLA)

com o sistema de informação do Ministério da Saúde, eles não provocam em nome da independência federativa da autonomia federativa - não é nem independente, autonomia federativa - "mas não posso intervir no estado", mas quando eles querem eles podem.(UNEGRO) 
Nesse particular, apontam os principais elementos de divergências do ponto de vista técnico e administrativo:

Então precisa maior investimento financeiro no mecanismo de gestão competente pra gestão do antirracismo no SUS, o SUS garantindo que o financiamento não seja uma partição do SUS, mas que altere a lógica do SUS, pra ele poder ser acolhido, pra política nacional de saúde da população negra ser bem sucedida. (CRIOLA)

houve um grande empenho, isso eu não posso negar. Mas se o empenho tivesse sido maior, a política teria sido de fato implementada, porque por mais... que... o governo federal ele não pode obrigar, aí a gente sabe que o SUS ele tá nas três esferas de governo, a gente sabe que o ministério não pode obrigar, mas... ele tem uma força de pressão! (FENAFAL)

uma outra coisa também que o próprio Ministério da Saúde fortaleceu, é não ter comitês técnicos de saúde da população negra. Fica no comitê de equidade. Quando você coloca no comitê de equidade, você amplia... o número de pessoas, o número de ações e... o número de problemas, porque no comitê de equidade está muita gente... da população ribeirinha, população LGBT, população indígena, população quilombola... (UNEGRO)

É um obstáculo você não ter pessoas preparadas que conheçam a importância da saúde pra gerenciar desde o ministério até o município. Nós não temos. (ACMUN)

Uma das lideranças questiona a relação estabelecida entre o poder político e o poder técnico no âmbito do MS.

[...] em termos de dados também hoje você tem muitos dados e dizer que tem falta de dados, mentira, existe dados, né, existe os dados. Mas não tem decisão política a partir desses dados. Ué? Pra quê existem dados 
então? Se eu tenho todos os dados e eu não tomo a decisão política a partir desses dados, nada vai acontecer. (RENAFRO)

Ainda, em termos de divergências com o MS, as lideranças veem incompatibilidade entre a política e a instância institucional de execução da mesma.

... O Ministério da Saúde chamou pra... reestruturar o comitê técnico de saúde da população negra e... foi criada uma área que vai ficar abaixo do que a saúde da população negra já esteve. Então ela é executada pela Secretaria de Gestão Estratégica e Participativa (SGEP) e... mais especificamente dentro de um departamento da SGEP. E agora ela está abaixo desse departamento. Então é muito complicado tu achar que uma política nacional que deve dar conta de toda uma população, em relação à saúde, possa ser executada por uma 'sub-cordenação'. (ACMUN)

Em relação à proposta de reorganização do CTSPN, chama atenção a fala de alguns entrevistados que expressam implicitamente uma certa dissonância sobre a questão.

[...] no comitê técnico de saúde da população negra hoje tem uma mudança no comitê, sai todos os pesquisadores e os militantes que já eram antigos pra entrar novos militantes. Se é bom? É. Mas tem uma coisa nessa novidade... é que alguns desses que estão entrando detém poucas informações e quem detém informação, detém poder. (RENAFRO)

Não aceitavam que como ativistas participássemos de um órgão consultivos que forneceria insumos pro ministério da saúde construir uma política duma área que ele desconhecia e que até hoje desconhece, né?! que é o antirracismo. Então, achava que não tínhamos pra sermos aceitas e aceitos pelos brancos, pelos dirigentes, 
o acordo que a SEPPIR fez foi nos chamar de pesquisadores e pesquisadoras. (CRIOLA)

[...] esse comitê [CTSPN] sendo reestruturado perde completamente o seu papel fundamental que é assessorar tecnicamente o Ministério da Saúde. A ideia agora é colocar maioria de sociedade civil de organizações da sociedade civil, que são importantes sim... mas muitas vezes não vão responder para questões técnicas. Uma coisa é... ter conhecimento de qual é minha direção comunitária e conseguir colocar minha demanda, mas pra assessorar tecnicamente o Ministério tem que ser pesquisadores e esse comitê vem sendo. reestruturado, diminuindo o numero de pesquisadores! O que perde todo o sentido?! Não vai ser mais um comitê, vai ser uma comissão formada por entidades e a gente se posicionou contra. (ACMUN)

Pelo exposto, é possível perceber que as diferenças entre essas lideranças sobre o CTSPN, refletem uma discrepância com a redefinição das funções e competências dessa instância, que para alguns deve ter um caráter político e para outros um caráter mais técnico. De um modo geral, apesar das diferenças do ponto de vista técnico, político e administrativo, há certa consonância no discurso das lideranças. Porém, isso não implica em homogeneidade do Movimento que, ao contrário, apresenta discordâncias entre as próprias lideranças que atuam na saúde e dessas com o conjunto maior do Movimento Negro em relação ao curso da atuação política.

\section{Para além das estratégias setoriais: consonâncias e diferenças no Movimento}

Além da atuação no CNS, uma das principais estratégias referidas pelo conjunto de lideranças diz respeito à fundamentação legal da PNSIPN, tendo em vista que esta deixe de ser somente uma portaria do MS e alcance o status de lei a partir do Estatuto da Igualdade Racial. 
A gente trata o estatuto como lei. A gente tem esse estatuto como se fosse a bíblia dentro da nossa organização. A gente distribui pra a população que a gente trabalha, [... sempre que pauta a questão da saúde da população negra, a gente pauta como lei, porque o primeiro artigo do estatuto tem a questão da saúde!

As lideranças, porém, apresentam diferenças no entendimento do conteúdo do Estatuto. Embora a maioria delas acredite que o fato da PNSIPN ter se tornado lei consista em um avanço, duas posições sobre o tema deixam mais explícita algumas discordâncias sobre essa questão.

Deixou de fora quilombolas, deixou de fora um montão de pautas que tava aguda e importante pra o movimento. Vi o estatuto da igualdade racial naquele momento como uma derrota, mas depois daquele momento vejo ele como uma lei né? 'Uma lei que também tá sendo fruto de disputa, porque as leis nos Brasil elas são fruto de disputa, não é?'

Um ganho para o movimento negro. Pra a sociedade brasileira [...] ele não traz 'dinheiro' para fazer o que ele prega. Esse é o ponto fraco! Não tem pontos fracos... é 'um' ponto fraco.

O processo de mobilização da sociedade civil em torno da aprovação do Estatuto da Igualdade Racial evidenciou, portanto, importantes tensões no que diz respeito à relação das organizações do Movimento Negro com o governo, permeadas por relações político-partidárias:

[...] houve um embate muito duro do movimento negro, dos partidos pra aprovação do estatuto contra nós que dizíamos que tinha que não podia ser a qualquer custo. muito... difícil. De você ver companheiros negros combativos que foram referência pra mim, ou pro movimento ou pra outros. Naquele espaço de lá de dentro 
da corda, sabe assim, fazendo defesa de coisas que nem eles acreditavam, mas que tinham que fazer por um compromisso partidário?! [...] o estatuto da igualdade racial não seria a lei que eu ou que o setor político que eu represento aprovaria e diria que tá fazendo em defesa da população negra, foi basicamente uma conveniência politica, os partidos quiseram mostrar alguma coisa no processo eleitoral deles. (CRIOLA)

Outros entrevistados denunciam essa situação, apontando as dificuldades enfrentadas em outros espaços institucionais, em virtude da mudança de posição de antigos companheiros que passaram a fazer parte do governo, ocupando cargos na burocracia estatal:

[...] vão às reuniões, escutam, mas dão as costas e parece que nada aconteceu. Fazem o que querem. E por outro lado isso é bem complicado, porque estamos lidando com pessoas da sociedade civil que hoje estão no Governo, sempre foram nossos parceiros, sempre estiveram do nosso lado, [...] E é nesse sentido que a gente acaba não fazendo, enquanto a ACMUN, essa filiação partidária! ela é muito complicada assim nesses momentos, assim. (ACMUN)

Porque a partidarização do movimento compromete o controle social... das politicas publicas, entendeu? Primeiro vira um pouco de chantagem, quando você vai pra cima de um... do governo ou do Estado, dizendo: 'Olha, as políticas não tão sendo implementadas' e demonstra com dados... ah... tem um seguimento do movimento que diz: 'Não... mas pera aí... tem lei...', enfim, a partidarização dificulta muito o controle social em relação a implementação de políticas. (GELEDES)

As lideranças apresentam diferentes visões acerca da relação entre as organizações e os partidos políticos. Algumas organizações defendem a importância do partido político para os movimentos sociais como forma de ampliar suas pautas para o conjunto da socieda- 
de, bem como potencializar a sua intervenção no Estado, seja elegendo parlamentares ou interferindo na elaboração de políticas públicas. (Unegro, Fenafal e Renafro)

Já outra organização defende a necessidade de não partidarização como estratégia de maior flexibilização na negociação com diferentes governos de diferentes orientações partidárias (ACMUN). Porém, duas das organizações são enfáticas em afirmar a necessidade de distanciamento entre o partido e o movimento social, reivindicando a "autonomia" como elemento importante para garantir a integridade das bandeiras de luta.

[...] a gente não tem 'muita' proximidade com... o movimento negro partidário né?!, assim, e tem algumas organizações muito partidárias, particularmente ligadas aos partidos $\mathrm{PSB}, \mathrm{PT}, \mathrm{PCdoB}$ né?! que são as maiores organizações partidárias entre nós, mas também tem organizações de PSOL, a gente não quer muita ligação com partido... com as organizações partidárias porque eu acho que... aí não é agenda do antirracismo?! é agenda do que tem sido, mais infelizmente, agenda do partido participando do antirracismo e dos seus próprios termos e não dos termos que o antirracismo permite, muito menos do antirracismo patriarcal e do interesse das mulheres negras. (ACMUN)

a ACMUN não levanta bandeira partidária! 'sempre' teve relação com governos, então pra nós é muito' complicado, sempre teve projeto financiado pelos governos né?!. Não quer dizer que a gente não vote no PT ou que a gente não faça de alguma maneira campanha 'pra' candidatos negros que estãono PT ou que estão no campo de esquerda... no nosso campo político, mas sempre 'absolutamente' mantendo a nossa independência... (ACMUN)

Como a UNEGRO não é partido a gente tem que ta em algum partido, então a maioria deles são do PCdoB. Como tem do PDT conheci vários agora no encontro de 
mulheres. São da UNEGRO e são do PDT.Tem PSB... (UNEGRO)

A gente faz política, mas não faz política partidária [...] mas na medida que você tem uma bancada evangélica muito forte, uma bancada católica, nós também vamos ter que fazer os nossos, entendeu? Para que possam também essar dialogando, para que possam defender causas nossas. (RENAFRO)

Chama atenção que as mesmas organizações que apresentam diferenças em relação aos partidos nos movimentos sociais recorreram aos partidos da base aliada do governo para articular a pauta de saúde da população negra no estatuto:

Na feitura do estatuto de igualdade racial... a deputada Janet Pietá $[P T]$ liderou junto com um grupo de parlamentares, da frente parlamentar do antirracismo, frente parlamentar negra [Frente Parlamentar Mista da Igualdade Racial], mas foi ela que nos levou ao debate, foi ela que negociou, que nós negociamos com ela que se o estatuto da Igualdade Racial vai ter um capitulo de saúde que ele fosse nos mesmos termos com que a gente construiu a Política Nacional de Saúde Integral da População Negra [...] deputado Luís Alberto, que é do PT, e deputado Daniel Tourinho, PCdoB, e deputado Carlos Santana PT. (CRIOLA)

Desse modo, as disputas políticas engendradas pelas lideranças das organizações do Movimento Negro, em alguma medida passam pela mediação dos partidos políticos, seja no interior do próprio Movimento, através de lideranças que militam nessas organizações, no parlamento, através dos deputados e senadores de partidos que apoiam bandeiras das questões raciais, e até mesmo no executivo, por meio da gestão. Embora no marco geral todas essas organizações estejam situadas em um mesmo "campo político", essas relações, na visão dessas lideranças, alterna-se entre tensão e cooperação, a depender da conjuntura específica e dos interesses estratégicos em jogo. 


\section{Movimento Negro na saúde e os paradoxos na ação}

A visão das lideranças sobre a situação do racismo e da saúde no Brasil, expressa, em alguma medida, a complexa conjuntura política frente a governos de expoentes contradições nos últimos 10 anos. Se, por um lado, essas organizações encontram na sociedade civil apoio dos partidos que historicamente deram suporte às suas reivindicações, por outro encontram obstáculos com esses mesmos partidos, frente aos interesses macropolíticos e econômicos do governo, em aliança com setores da classe dominante, conforme aponta Coutinho (1993), e que em alguns momentos se confrontam com os interesses desse coletivo de organizações.

O mito da democracia racial, ou "racismo à brasileira" (TELLES, 2003), consenso construído pelas classes dominantes entre as classes subalternas, vem sendo cada vez mais problematizado pelas organizações da sociedade civil. $\mathrm{O}$ aumento do número de denúncias de discriminação racial por parte de pessoas não organizadas na sociedade civil dá indícios sobre as conquistas alcançadas a partir da disputa ideológica desenvolvida pelo conjunto do Movimento Negro na sociedade brasileira.

Por outro lado, a diversificação das estratégias de repactuação desse consenso por parte das classes dominantes modela novas configurações dessa disputa. Ao mesmo tempo em que o Governo Federal reconhece a existência do racismo, negada por tantos anos, também disputam os conteúdos políticos e ideológicos dessa problemática, o que se reflete inclusive na limitação de recursos para a execução de ações de grande amplitude.

Na saúde, ao mesmo tempo em que estabelecem o fortalecimento do SUS no programa de governo, ao negligenciarem as determinações sociais na saúde, restringindo a saúde aos limites da oferta de serviços, centrado nas tecnologias de alta complexidade, refletiriam segundo (TEIXEIRA, 2001) a manutenção do modelo médico-hegemônico. Excluindo as ações de promoção, o Estado constrói consensos em torno de uma visão hegemônica da saúde, abrindo es- 
paço para a participação de setores privados, que disputam o financiamento destinado ao setor. (SCHEFFER, 2015)

Porém, a percepção dessas contradições por parte das lideranças não os colocam em oposição frontal em relação ao governo, muito menos desautoriza o Estado enquanto possibilidade de concretização de suas pautas reivindicatórias. Ao contrário colocam-se na posição de buscar negociações com vistas a garantir, ainda que de maneira parcial, avanços em relação a implementação da Política Nacional Integral de Saúde da População Negra.

Nesse particular, vale dessacar que o racismo enquanto ideologia dominante atravessa todas as práticas sociais, inclusive as práticas de saúde. Embora se expresse concretamente nos atos de preconceitos e discriminação racial, no âmbito das relações interpessoais entre profissional-usuário nos serviços de saúde, na estereotipação das pessoas negras, na incipiente produção técnico-científica das doenças que prevalecem na população negra, na resistência das políticas de saúde em reconhecer as desigualdades raciais, o racismo não se resume a essas práticas da vida cotidiana.

Porém, a abordagem dessa questão por parte desse coletivo de organizações situa-se no entrelaçamento entre a problemática da discriminação racial e a precarização do Sistema Único de Saúde, que tem implicações negativas no acesso aos serviços de saúde e no perfil de morbimortalidade da população negra, constituindo-se uma complexa arena de tensões (CORTES, 2009) entre as lideranças do movimento negro e gestores da saúde no que diz respeito à implementação da PNSIPN.

Uma vez que as políticas de saúde estejam relacionadas com a distribuição de poder, as estratégias empreendidas por essas lideranças no âmbito do setor saúde também expressam o conteúdo dos projetos pretendidos. $\mathrm{O}$ deslocamento de recursos técnicos, financeiros e administrativos com objetivo de modificar as ações em relação à saúde da população negra no âmbito da gestão, dos serviços de saúde, da formação de pessoal e do sistema de informação, não encerram em si o projeto dessas organizações. 
No caso da PNSIPN quando optam por participar do jogo institucional (TESTA, 1995), elas entram com o intuito de modificar comportamentos dos agentes do Estado, e das próprias instituições em relação ao racismo na saúde, para que desenvolvam práticas políticas em favor da população negra. Por sua vez, o MS, detentor do poder técnico e do poder administrativo, maneja politicamente conforme os interesses estratégicos do governo.

No que diz respeito à correlação de forças no âmbito do MS, o poder político adquirido por essas organizações do Movimento Negro pode ser compreendido, a partir da legitimidade conferida pela sociedade civil pelo seu histórico de intervenção no enfrentamento as desigualdades raciais na saúde. Entretanto, a capacidade de distribuição de recursos, elaboração de informações e decisão, conduzida pela burocracia estatal se faz pouco permeável, na prática, a acolher o tema racial no setor saúde. Restringe a condução da política a uma estrutura institucional do MS com fortes limitações para gerar impactos sobre outros setores governamentais (educação, trabalho, previdência etc.) de modo a "transversalizar" a Política.

Assim, a aparência técnica na implementação das PNSIPN, na verdade, esconde os interesses em disputa no âmbito da sociedade política e da sociedade civil. A correlação de forças no âmbito da gestão na saúde se dá de maneira desequilibrada, tendo nas organizações do Movimento Negro seu elo mais frágil. Contudo, a estratégia de ampliar a questão da saúde da população negra para uma responsabilidade não só do MS, mas de todo o Estado brasileiro, através da lei do Estatuto da Igualdade Racial, demonstra a dinamicidade do Movimento em reorientar suas estratégias diante dos obstáculos e constituir alianças com outras instituições, como é o caso da Seppir.

Desse modo, por dentro dessas instituições do executivo estabelecem-se também o poder de diversificadas forças políticas que compõem o governo, podendo existir instâncias com maior interlocução com as ONGs e movimentos sociais, como é o caso da Seppir ou com menos interlocução, onde predomina a perspectiva técnico-burocrática, como caso do MS, principal espaço de decisão em 
relação à Política. Porém, essas diferenças não sugerem dissonância na forma de condução da política governamental, e sim, variadas estratégias de construção de consensos por parte do Estado.

Com isso, verifica-se não existir uma divisão esquemática entre sociedade política como espaço do uso da força e sociedade civil como espaço da construção do consenso. Não sendo possível, portanto, tomar o Estado como um bloco monolítico, ainda que no conjunto desenvolva ações em uma direção política e ideológica majoritária. (GRAMSCI, 2000)

Nesse sentido, a construção de consensos em torno do projeto social dos partidos que compõem o governo não está isenta de dissonâncias no desenvolvimento da prática política na relação com essas organizações do Movimento Negro. As tensões entre parte das lideranças que se reivindicam apartidárias e as lideranças partidárias expressam de alguma forma a resistência à cooptação por parte do Estado. Porém, essa desconfiança de cooptação, atribuída ao papel dos partidos no seio dos movimentos sociais apresentam contradições no seu desenvolvimento prático, uma vez que nenhuma das lideranças se opõe ao projeto estratégico disputado por essas organizações partidárias na sociedade brasileira.

Nesse caso, parece tratar-se de uma concepção que compreende a sociedade civil como algo que está fora da órbita do Estado, configurada como espaço para se buscar soluções para as questões econômicas, políticas e sociais. Nessa direção, as organizações das classes subalternas deveriam orientar suas demandas para a defesa de interesses puramente corporativos e setoriais. Porém, ainda que não pareçam dispor de vinculação partidária direta, ao identificarem esses partidos como aliados, inclusive no âmbito do poder legislativo, agem politicamente em consonância com a agenda governamental defendida por esses parlamentares no Congresso. Desse modo, as disputas empreendidas pelo coletivo de organizações do Movimento Negro na saúde também refletem os interesses das forças políticas com as quais se identificam em seus projetos societários. 


\section{Considerações finais}

Ao investigar a visão das organizações do Movimento Negro acerca da participação e avaliação política do processo de implementação da PNSIPN, demonstramos as contradições subjacente ao discurso das lideranças. Ao mesmo tempo em que situam relevantes ações por parte do governo na temática racial, reconhecem um atraso no setor saúde, contradições essas que podem ser interpretadas pelas disputas políticas em relação a temática, evidenciada no processo de elaboração e aprovação da lei Estatuto da Igualdade Racial.

Em suma, essas organizações partem das demandas vivenciadas pela população negra no que diz respeito ao direito à saúde para formular e atuar no campo da saúde, reproduzindo uma visão setorial sobre a questão, ainda que no marco da defesa do SUS e da transversalização da sua pauta nos diversos serviços e âmbitos do sistema. Esse processo acaba por expressar certo distanciamento da atuação das organizações desse Movimento com os pressupostos do Movimento da Reforma Sanitária, ao tempo que o Movimento Sanitário, ao propor uma "revolução no modo de vida" (PAIM, 2008), parece não contemplar em sua elaboração a centralidade o debate racial, para pensar uma verdadeira democratização da saúde brasileira, visto que a população negra compõe a maior parte dessa população em todo território.

Por fim, este estudo aponta para a necessidade de uma maior articulação do Movimento Negro com o Movimento da Reforma Sanitária. A interpretação das lacunas do Movimento Negro, tomando como referência o debate acumulado no Movimento Sanitário, não diminui o papel protagonista que este pode cumprir no campo da saúde. Ao contrário, busca lançar luz para seu fortalecimento, e reflexões não só para o Movimento Negro, mas principalmente para aqueles compromissados com a Reforma Sanitária Brasileira, afim de repensarmos a superação desse capítulo da história social brasileira que é a persistência da marginalização da população negra. 


\section{Referências}

ADORNO, R. C. F.; ALVARENGA, A. T.; VASCONCELLOS, M. P. Quesito cor no sistema de informação em saúde. Estudos Avançados, São Paulo, v. 18, n. 50, p. 119-123, 2004.

ALMEIDA, M.V.B. Caminhos da Política Nacional de Saúde da População Negra: Ideias, Atores, Interesses e Institucionalidade. 2013. $100 \mathrm{f}$. Dissertação (Mestrado em Ciências da Saúde) - Faculdade de Ciências da Saúde, Universidade de Brasília, Brasília, DF, 2013.

ARAUJO, M. V. R.; TEIXEIRA, C. F. A participação dos atores na formulação da política de saúde da população negra na cidade de Salvador. Physis, Rio de Janeiro, v. 23, n. 4, dez. 2013. Disponivel em: $<$ http://www.scielo.br/scielo.php?script=sci_arttext\&pid= S010373312013000 400004\&lng=en\&nrm=iso >. Acesso em : 30 mar. 2015.

BENTES, N. Brasil-Durban-Brasil: um marco na luta contra o racismo. Revista Estudos Feministas, Florianópolis, v. 10, n. 1, p. 229-236, 2002. BERNARDES, A. G. Saúde indígena e políticas públicas: alteridade e estado de exceção. Interface, Botucatu, v. 15, n. 36, mar. 2011.

Disponívele em: <http://www.scielo.br/scielo.php?script=sci arttext\&pid $=S 141432832011000100012 \& \operatorname{lng}=$ en $\& n r m=i s o>$. Acesso em: 4 abr. 2015

BRASIL, S. A. A Política de Saúde da População Negra no Brasil: atores políticos, aspectos étnico-raciais e principais tensões do campo. 2011. 147 f. Dissertação (Mestrado em Saúde Comunitária) - Instituto de Saúde Coletiva, Universidade Federal da Bahia, Salvador, 2011.

BRASIL. Ministério da Saúde. Secretaria de Gestão Estratégica e Participativa. Política Nacional de Saúde integral da população negra: uma política para o SUS. Brasília, DF, 2009. Disponível em:<http://bvsms. saude.gov.br/bvs/saudelegis/gm /2009/prt0992_13_05_2009.html>. Acesso em: 30 nov. 2013.

CARNEIRO, S. A batalha de Durban. Revista Estudos Femininos. Florianópolis, v. 10, n. 1, p. 209-214, 2002. 
CORTES, S. V. Sistema Único de Saúde: espaços decisórios e a arena política de saúde. Caderno de Saúde Pública, Rio de janeiro, v. 25, n. 7, p. 1626-1633, 2009.

COUTINHO, C. N. De Rousseau a Gramsci: ensaios de teoria política. São Paulo: Boitempo, 2011. 184p.

COUTINHO, C. N. As categorias de Gramsci e a realidade brasileira. In: COUTINHO, C.N.; NOGUEIRA, M. A. Gramsci e a América Latina. Rio de Janeiro: Paz e Terra, 1993. p. 103-127.

COUTINHO, C. N. A hegemonia da pequena política. In: OLIVEIRA, F.; BRAGA, R.; RIZEK, C. (Org.). Hegemonia às avessas. São Paulo: Boitempo, 2010.p. 29-43

DOMINGUES, P. Movimento negro brasileiro: alguns apontamentos históricos. Tempo, Rio de Janeiro, v. 12, n. 23, p. 100-1 22, 2007.

FERNANDES, F. A integração do negro na sociedade de classes: o legado da raça branca. 3. ed. São Paulo: Ática, 1978.

FERRAZ, J. M; SANTOS FILHO, A. O pós-abolição na Bahia: memória à construção da vida livre. In: NASCIMENTO, A. D.; HETKOWSKI, T. M. (Org.). Memória e formação de professores. Salvador: EDUFBA, 2007. p. 17-42.

FLEURY, S.; OUVERNEY, A. M. Políticas de Saúde: uma política social. In: GIOVANELLA, L. et al. (Org.). Políticas e Sistemas de Saúde no Brasil. Rio de Janeiro: Ed. Fiocruz, 2008. p. 23-64

GOHN, M.G. Teorias dos movimentos Sociais: paradigmas clássicos e contemporâneos. São Paulo: Loyola, 2011.

GRAMSCI, A. Cadernos do cárcere. Rio de Janeiro: Civilização Brasileira, 1999. v. 1.

GRAMSCI, A. Cadernos do cárcere. Rio de Janeiro: Civilização Brasileira, 2000. v. 3.

GRIN, M.; MAIO, M. C. O antirracismo da ordem no pensamento de Afonso Arinos de Melo Franco. Topoi, Rio de Janeiro, v. 14, n. 26, p. $33-$ 45, 2013. 
GUIMARÃES, A. S. A. A questão racial na política brasileira (os últimos quinze anos). Tempo Social, São Paulo, v. 13, n. 2, p. 121-142, 2001.

JACCOUD, L.O Combate ao racismo e à desigualdade:o desafio das políticas públicas de promoção da Iguaçdade Racial. In: THEODORO, M. (Org.). As políticas pú- blicas e a desigualdade racial no Brasil: 120 anos após a abolição. Brasília, DF; Instituto de Pesquisa Econômica Aplicada, 2008. p. 176.

KÖSSLING, K.S. As lutas anti-racistas de afro-descendentes sob vigilância do DEOPS/SP (1964-1983). 2007. 314 f. Dissertação (Mestrado em História Social) - Faculdade de Filosofia e Ciências Humanas, Universidade de São Paulo, São Paulo, 2007.

LIMA, M. Desigualdades raciais e políticas públicas: ações afirmativas no governo Lula. Novos Estudos. - CEBRAP, São Paulo, n. 87, p. 77-95, 2010.

LEITÃO, L. R. S. Oportunidades políticas e repertórios de ação: o movimento negro e a luta de combate. 2012. $152 \mathrm{f}$. Tese (Doutorado em Sociologia) - Instituto de Filosofia e Ciências Humanas da Universidade Federal Universidade Federal do Rio Grande do Sul, Porto Alegre, 2012. LOPES, F. Para além da barreira dos números: desigualdades raciais e saúde. Caderno de Saúde Pública, Rio de Janeiro, v. 21, n. 5, p. 595-160, 2005.

MAHER, C. M. Nem tudo é estar fora: o movimento de mulheres negras e as articulações entre saúde e raça. 2005. 146 f. Dissertação (Mestrado em Antropologia Social) - Instituto de Filosofia e Ciências Humanas, Universidade Estadual de Campinas, Campinas, 2005.

MELLO, L. et al. Políticas de saúde para lésbicas, gays, bissexuais, travestis e transexuais no Brasil: em busca de universalidade, integralidade e equidade. Sexualidad, Salud y Sociedad, Rio de Janeiro, n. 9, p. 7-28, 2011. Disponível em: <http://www.scielo.br/scielo.php?script=sci_ arttext\&pid $=$ S198464872011000400002\&lng $=$ en\&nrm=iso $>$. Acesso em: 4 abr. 2015.

NOGUEIRA, M. A. Um Gramsci todo dedicado à política. In : KRITSCH, R.; MELLO, L. I. A; VOUGA, C. Oliveiros S. Ferreira : um pensador da política. São Paulo: Humanitas, 1999. p. 133-156. 
OLIVEIRA, F. Saúde da População Negra: Brasil, ano 2001. Brasília, DF: Secretaria Especial de Políticas de Promoção da Igualdade Racial. Brasília, 2001.

OSIS, M. J. M. D. Paism: um marco na abordagem da saúde reprodutiva no Brasil. Caderno de Saúde Pública, Rio de Janeiro, v. 14, n. 1, 1998. Suplemento. Disponível em: <http:// www.scielo.br/scielo.php?script=sci_arttext\&pid=S010231 1X1998000500011\&lng=en\&nrm=iso >. Acesso em: 4 abr. 2015.

ORGANIZAÇÃO PANAMERICANA DA SAÚDE-OPAS. Seminário Política Nacional de Saúde da População Negra: uma questão de equidade. Brasília, DF, 2001.

PAIM, J. S. Reforma sanitária brasileira: contribuição para compreensão e crítica.Salvador: EDUFBA, 2008.

PIANA, M. C. As políticas sociais no contexto brasileiro: natureza e desenvolvimento. In: PIANA, M. C. A construção do perfil do assistente social no cenário educacional. São Paulo: Editora UNESP; Cultura Acadêmica, 2009. p. 21-56.

PINTO, E. A.; SOUZAS, R. Etnicidade e saúde da população negra no Brasil. Cadernos de Saúde Pública, Rio de Janeiro, v. 18, n. 5, p. 1144-1145, 2002.

PINTO, C. R. J. As ONGs e a política no Brasil: presença de novos atores. Dados: Revista de Ciências Sociais, Rio de Janeiro, v. 49, n. 3, 2006. Disponível em: <http://www.scielo.br/scielo.php?script=sci_ arttext\&pid=S001152582006000300008\&lng=en\&nrm=iso $>$. Acesso em: 30 mar. 2015.

PINTO, I. C. M; VIERA-DA-SILVA, L.M; BAPTISTA, T.V. F. Ciclo da Política: problematização, construção da agenda, institucionalização, formulação, implementação e avaliação. In: PAIM, J. S.; ALMEIDAFILHO, N. A. Saúde Coletiva: teoria e prática. Rio de Janeiro: MedBook, 2014. p. 69-81.

RAMOS, S. O papel das ONGs na construção de políticas de saúde: a Aids, a saúde da mulher e a saúde mental.

Ciência Saúde Coletiva, Rio de Janeiro, v. 9, n. 4, dez. 2004. 
Disponível em:<http://www.scielo.br/scielo.php?script=sci arttext\&pid=S141381232004000400027\&lng=en\&nrm=iso $>$. Acesso em: 30 mar. 2015

RIOS, F. O protesto negro no Brasil contemporâneo (1978-2010). Lua Nova, São Paulo, p. 41-79, n. 85, 2012. Disponível em: <http://www.scielo.br/scielo.php?script=sci arttext\&pid $=$ S010264452012000100003\&lng=pt\&nrm $=$ iso $>$. Acesso em: 17 mar. 2015.

RIVERA, F. J. U. A teoria do planejamento estratégico no setor social e da saúde à luz do agir comunicativo: o contexto latino-americano. In: RIVERA, F. J. U. Agir comunicativo e Planejamento Social. Uma crítica ao enfoque estratégico. Rio de Janeiro: Ed. Fiocruz, 1995. p. 144-211.

SCHEFFER, M. O capital estrangeiro e a privatização do sistema de saúde brasileiro. Caderno Saúde Pública, v. 31, n. 4, p. 663-666, 2015.

SEMERARO, G. Gramsci e os novos embates da filosofia da práxis. Aparecida, SP: Idéias \& Letras, 2006. SILVA, F.O. Os negros, a constituição de espaços para os seus e o entrelaçamento desses espaços: associações e identidade em Pelotas (1820/1943). 2011. 228 f. Dissertação (Mestrado em História) Pontifícia Universidade Católica do Rio Grande do Sul, Porto Alegre, 2011.

SILVA, J. A União dos Homens de Cor: aspectos do movimento negro dos anos 40 e 50. Estudos Afro-Asiáticos, Rio de Janeiro, v. 25, n. 2, p. 215-235, 2003.

TEIXEIRA, C. F. O futuro da prevenção. Salvador: Casa da Qualidade, 2001.

TELLES, E. Racismo à brasileira: uma nova perspectiva sociológica. Rio de Janeiro: Relume-Dumará: Fundação Ford, 2003.

TESTA, M. Pensamento estratégico e lógica de programação: o caso da saúde. São Paulo: Hucitec; Rio de Janeiro: ABRASCO, 1995.

TORRONTEGUY, M. A. A.; DALLARI, S. G. O papel das organizações não-governamentais na cooperação internacional em 
saúde pública. Saude Sociedade, São Paulo, v. 21, n. 2, jun. 2012.

Disponível em: <http://www.scielo.br/scielo.php?script=sci

arttext\&pid=S010412902012000200006\&lng=pt\&nrm=iso $>$. Acesso

em: 30 mar. 2015

TESTA, M. Pensar em saúde. Porto Alegre: Artes Médicas: ABRASCO, 1992.

TRAPP, R. P.; SILVA, M. L. da. Movimento Negro no Brasil contemporâneo: estratégias identitárias e ação política. Revista Jovem Pesquisador, Santa Cruz do Sul, v. 1, p. 89-98, 2010.

VIANNA, A. L. D.; BAPTISTA, T. W. F. Análise de políticas de saúde. In: GIOVANELLA, L. et al. (Org.). Políticas e sistema de saúde no Brasil. Rio de Janeiro: Ed. Fiocruz, 2008. p. 65-105.

VASCONCELOS, K. E. L; SILVA, M. C.; SCHAMLLER. V. P. V. (Re) visitando Gramsci: considerações sobre o Estado e o poder. Revista katálysis, Florianópolis, v. 16, n. 1, p. 82-90, 2013. 
Anexo - Trajetória metodológica do capítulo

Esta pesquisa fez parte da execução do projeto do doutorado em Saúde Coletiva, desenvolvido no Programa de Pós-Graduação em Saúde Coletiva do Instituto de Saúde Coletiva da Universidade Federal da Bahia (PPGSC/ISC/UFBA), no período de 2011 a 2014. Trata-se de um estudo centrado na produção e análise de informações qualitativas acerca das concepções e práticas de lideranças do Movimento Negro com relação à problemática de saúde. Fez parte deste estudo lideranças de entidades e organizações do Movimento Negro (ONGs, religiosas, políticas, associações etc.) que desenvolvem práticas relacionadas ao que vem sendo denominado de "campo de saúde da população negra", no âmbito da sociedade civil e das instituições públicas do Governo Federal. Inicialmente, foi feito a exploração, através do Google, das entidades e organizações do Movimento Negro que participaram dos principais eventos nacionais da sociedade civil impulsionados pelo Movimento Negro nos últimos 15 anos (Seminários de Articulação Pré-Durban; Seminários Nacionais de Saúde da População Negra; Comitê de Organização Zumbi + 10 - II Marcha contra o Racismo, pela Igualdade e a Vida debates sobre o Estatuto da Igualdade Racial). Uma vez gerada uma lista de 15 organizações, foram selecionadas aquelas com intervenção nacional. Em seguida, o nome das organizações foi associado ao termo "saúde", e depois "saúde da população negra" chegando-se a um número de 11 entidades. Posto isso, foi feito o contato com uma liderança cujo nome estava entre os 11 e, através da técnica da bola de neve e posterior comparação com a lista dos 11, chegou-se a um conjunto final de nove, das quais uma não se sentiu apta a abordar sobre tema e as outras duas não retornaram contato.

Os dados foram produzidos, entre os meses de abril e agosto de 2014, através de entrevistas online, via SKYPE e software de gravação Audacity (4), e presenciais, com uso de gravador (2), utilizandose um roteiro de entrevista semiestruturada à visão das lideranças destas organizações sobre o processo de implantação da PNSIPN. Os discursos produzidos através das entrevistas foram transcritos 
e organizados em matrizes de dados com base no quadro teórico e tendo referência no método SWOT (OPS, 1994), contemplando os seguintes aspectos: a) caracterização do cenário: diz respeito ao contexto político e institucional onde se desenvolvem as ações do Movimento Negro, ou seja, se as ações do governo em relação ao tema racial convergem e/ou favorecem ganhos para o Movimento ou não; b) identificação dos aliados e oponentes, isto é, atores e políticos, tanto da sociedade civil quanto do Estado com os quais foi possível estabelecer relações de apoio total e/ou parcial (aliados) ou àqueles que não só divergem como também dificultam a criação de condições, seja de maneira explícita ou implícita, a decisões favoráveis ao processo de implementação da política (oponentes); c) facilidades/oportunidades bem como dificuldades/obstáculos que se apresentaram no processo.Uma vez organizados na matriz, foi utilizado a técnica de análise de conteúdo, com base nas categorias definidas no referencial teórico: sociedade política e sociedade civil; estratégia; poder e ideologia.

Por fim, cabe registrar que o projeto que deu origem a esta pesquisa foi submetido e aprovado no Comitê de Ética do ISC/UFBA, em conformidade com a Resolução CNS/MS 196/96. Todos os sujeitos foram orientados quanto à natureza e os objetivos da pesquisa e aceitaram participar da entrevista assinando o Termo de Consentimento Livre e Esclarecido, enviado por e-mail, assinado, digitalizado e enviado ao pesquisador, autorizando a reprodução de suas entrevistas no trabalho. 